hesitated to guess at the approximate solution of problems that at present are unsolved. ... We have chosen the experimental material, too, with a view to comparing it with our theory and our conjectures".

One is bound to ask, therefore, whether a strong case has been made for this theory as a basic interpretationhowever rough and uncertain in detail - of the observed phenomena. Is this how it really is? I must admit that I remain somewhat sceptical.

On the one hand, it is not at all obvious that the data themselves fully support the model. In almost every case, agreement between theory and experiment requires that some ill-defined quantity should take some value that has not been checked independently, or it is necessary to introduce one or another of several competing mechanisms that "may" also be acting. Nowhere in the book can I find a clear and simple situation where careful observation and explicit calculation come into close coincidence and where other explanations can be excluded. To achieve conviction by this route, the authors must not only demonstrate that the observations are not inconsistent with a plausibly modified version of their basic model, but they must also show that all competing theories are definitely falsified by the facts. Until that is done, we must remain agnostics, and treat all hypotheses with equal suspicion.

On the other hand, the authors do not demonstrate that their formulae are necessary consequences of the chemical and physical structure of the materials being studied. The Anderson localization theorem, for example, has been proved only for variations of potential in a tight-bound electron band: this proof has not yet been extended to structurally disordered systems such as glassy semiconductors. Again, the "Kubo-Greenwood Formula" (quoted without even a reference to Kubo's original derivation) is notoriously difficult to handle: qualitative dimensional manipulations can prove nothing without a solid backing of tough algebra on exact models. The authors refer in passing to a number of papers which attempt to discuss these points of principle, but cannot expect us to accept their model as necessarily true until they have dealt specifically with genuine objections at the fundamental level.

We must be grateful for the immense labour that the authors have put into collecting and collating these observations, and for the insight and courage of their interpretations and speculations. Nevertheless, on the theoretical side also, this subject is by no means a closed chapter of physics.

JOHN ZIMAN

\section{Aquatic Biomass}

Methods for the Estimation of Production of Aquatic Animals. Edited by G. G. Winberg. Translated from the Russian by Anne Duncan. Pp. xii 175. (Academic Press: New York and London, September 1971.) $£ 3$; $\$ 9$.

This useful book not only serves as a guide to methods for estimation of secondary production, but summarizes a considerable body of results. It is a translation of part of a handbook developed for use in the Soviet part of the International Biological Programme. Although it refers to western literature, it will be especially valuable as a review of work in the Soviet Union, much of it done under the leadership of the author.

The first part contains a brief review of methods for measuring and expressing biomass and its components, and discusses the effect of environmental conditions, especially temperature, on growth, development and fecundity. The bulk of the book is devoted to a review of various systems for calculating productivity, based on reproduction and growth. The discussion is divided between two chapters, one for species without continuous reproduction and one for the more difficult case of species with continuous reproduction. Many of the different systems of equations that have been developed by various investigators are merely different arrangements of different symbols representing the same functions, and Winberg points out a number of such identities.

The main approach is to calculate the mass of material that is added to a population during an interval of time, and sum the increments to give the annual total. The emphasis in the IBP view of production is on the tangible increment to the biomass of a population during a period of time. Thus missing from this book is any treatment of energy budgets with accounting of metabolic maintenance costs of populations and the like. The book provides an excellent summary of thinking and work on aquatic secondary production in the USSR. Those who have been bothered by the apparent redundancy of $P=P B \times B$ will find the most detailed explanation available.

There are relatively few ambiguities or errors; on page 124, the shortcut method of determining egg duration attributed to Tonolli is mis-described. In actual use each ovigerous female is kept isolated, and the production of new eggs is easily detected, so the duration of development is not likely to be overestimated. Furthermore, some of us feel that the reproductive rate of animals is clearly related to food, among other influential factors (page 64). Some of the methods discussed are in a primitive state of development, and some of them will probably not survive, for example, the use of the generation time for the doubling time.

The translation by Anne Duncan is excellent. The bibliography gives translations of Russian titles and cites sources of English translations of the articles.

This book should not be confused with IPB Handbook No. 17, edited by Edmondson and Winberg. That book covers a wider field including methods of collecting, of statistical analysis and of measurement of such basic processes as feeding, assimilation and respiration. The final chapter of No. 17, compiled by Winberg, reviews methods of calculation, covering much the same material as the book under review, but more briefly and without as much documentation by examples.

\section{W. T. EDMONDSON}

\section{Microbes of the Soil}

Soil Micro-organisms. By T. R. G. Gray and S. T. Williams. Pp. viii +240 +11 plates. (Oliver and Boyd: Edinburgh, August 1971.) $£ 3$.

THIS book is a well balanced text on soil microorganisms in relation to their environment and hence a good contemporary treatment of soil microbiology.

An interesting feature is the brief treatment given, where appropriate, to some physiological or biochemical pro. cess or theory relevant to the subject matter. Examples are the discussion of the regulating mechanism of enzyme production and the principle of the chemostat in relation to microbial ecology. This is not overdone and emphasizes the links between soil and general microbiology.

The book is written in a flowing, very readable style, is thorough, well illustrated, and almost free from misprints. It properly fulfils the purpose of the series in providing an authoritative up-to-date survey of its subject and is to be recommended as a university text. One mis-statement maintains the propagation of the old error that fungi are strict aerobes. For the more advanced reader the book is well worth having not only as a refresher course but for the statements expressed so that they challenge one to think. Why should "fungi and actinomycetes use a greater percentage of metabolized carbon than do bacteria", and how is it that "colonizers of freshly fallen leaves are generally rather uncommon species"-when $25,500 \mathrm{~kg}$ of tree litter falls on each hectare of forest? These, and others, are accepted propositions in soil microbiology. Should they be?

H. T. TRIBE 